\title{
Tamanho Relativo dos Órgãos Internos de Zebuínos sob Alimentação Restrita e Ad libitum $^{1}$ \\ André Mendes Jorge ${ }^{2}$, Carlos Augusto de Alencar Fontes ${ }^{3}$, Mário Fonseca Paulino 4 , Paulo Gomes Júnior 5
}

\begin{abstract}
RESUMO - Os efeitos do nível nutricional e da raça sobre o tamanho relativo dos órgãos internos foram estudados. Sessenta e três machos não-castrados, sendo 16 da raça Gir, 16 Guzerá, 16 Mocho de Tabapuã e 15 da raça Nelore, com idade média de 24 meses e pesos vivos médios iniciais de 376,4; 357,6;362,0; e 368,6 kg, respectivamente, foram usados. Os animais de cada raça foram divididos, aleatoriamente, em cinco categorias. Uma categoria foi abatida imediatamente (AB); três categorias receberam ad libitum ração contendo $50 \%$ de concentrado na matéria seca (categoria 1,2 e 3), em baias individuais; e uma categoria recebeu a mesma ração, em quantidade restrita, suprindo níveis de proteína e energia 15\% acima da mantença (AR). Os animais das categorias 1,2 e 3 foram abatidos ao atingirem pesos vivos individuais de 405, 450 e $500 \mathrm{~kg}$, respectivamente. No abate, o peso de corpo vazio (PCVZ) foi determinado e os pesos dos órgãos internos e víscera foram registrados. Não houve diferenças entre raças nos pesos de fígado, baço, intestinos delgado e grosso, rúmenretículo, omaso, estômagos e trato gastrintestinal (TGI), quando expressos em $100 \mathrm{~kg}$ de PCVZ. A restrição alimentar não influiu nos pesos do coração e dos pulmões, mas reduziu o peso do fígado e os componentes do TGI.
\end{abstract}

Palavras-chave: nível nutricional, órgãos internos, tamanho relativo, trato gastrintestinal, zebuínos

\section{Relative Size of Internal Organs of Zebu Cattle under Restricted and Full Fed Feeding}

\begin{abstract}
The effects of genetic group and nutritional level on relative size of internal organs were studied. Sixty-three bulls, 16 Gyr, 16 Guzera, 15 Nellore and 16 Mocho de Tabapuã, averaging twenty four months of age, and initial live weight of 376.4, 357.6, 362.0 , and $368.6 \mathrm{~kg}$, respectively were used. The animals from each breed were randomly assigned to five groups. One group was immediately slaughtered (AB), three groups were full fed, in individual free stall, a diet containing $50 \%$ of concentrate on dry matter basis (group1, 2 and 3), and one group was fed with a restricted amount of the same diet to supply the levels of protein and energy $15 \%$ above maintenance (AR). The animals of groups 1, 2 and 3 were slaughtered when they reached the individual live weights of 405,450 and $500 \mathrm{~kg}$, respectively. At slaughter, the empty body weight (EBW) was determined and the weight of internal organs and viscera were recorded. There were no differences among breed regarding to weight of liver, spleen, small and large intestines, reticulo-rumen, omasum, stomach and gastrointestinal tract (GIT), per $100 \mathrm{~kg}$ of EBW. The feed restriction did not affect the weights of heart and lungs, but reduced the weight of liver and GIT components.
\end{abstract}

Key Words: nutritional level, internal organs, relative size, gastrointestinal tract, zebu cattle

\section{Introdução}

O estudo quantitativo das partes não-integrantes da carcaça é importante, pois estas tendem a variar de acordo com a raça, tendo influência direta sobre o rendimento de carcaça e o ganho de peso. As diferenças que ocorrem nos tamanhos relativos dos órgãos internos, entre raças, podem também estar associadas a diferenças nas exigências de mantença. SMITH e BALDWIN (1973) mencionam que coração, fígado e trato gastrintestinal estão entre os tecidos de maior atividade metabólica nos animais.

Alguns autores têm observado menores pesos do trato gastrintestinal (TGI) de animais Nelore quando comparados a taurinos e/ou mestiços, principalmente de origem leiteira (GONÇALVES, 1988; PERON et al., 1993; e JORGE, 1993). Estas informações sugerem menor capacidade de ingestão de alimentos nos animais Nelore em relação aos taurinos e mestiços.

GALVÃO et al. (1991b), entretanto, verificaram maior peso do trato gastrintestinal (TGI) vazio, expresso em porcentagem do peso corporal vazio

\footnotetext{
1 Parte da Tese apresentada à UFV pelo primeiro autor, para obtenção do título de Doctor Scientiae. Trabalho realizado em colaboração com aEPAMIG/FAPEMIG.

2 Professor Assistente Doutor do DPEA/ UNESP - Faz. Lageado, Caixa Postal 560 - 18618-000 - Botucatu, SP.

E-mail: jorgeam@fca.unesp.br

3 Professor Titular UFV, Viçosa-MG/UENF, Campos-RJ. Bolsista do CNPq.

4 Professor do Departamento de Zootecnia da UFV, Viçosa-MG.

${ }^{5}$ Bolsista Iniciação Científica - FAPEMIG.
} 
(\%PCVZ), em animais Nelore, que em animais F1 Nelore-Marchigiana e F1 Nelore-Limousine.

HOGG (1991) afirma que, quando o estresse nutricional induz manutenção ou perda de peso, há declínio no peso e na proporção dos órgãos internos, particularmente de fígado, estômagos e intestinos.

Tem sido observado menor peso do TGI de bovinos Nelore submetidos à restrição alimentar, sugerindo possível atrofia do mesmo, em resposta ao baixo consumo alimentar (GALVÃO et al., 1991a; PERON et al. 1993; e JORGE, 1993).

PERON et al. (1993) e JORGE (1993) compararam bovinos (Nelore e mestiços) abatidos ao início do experimento (mais leves) com animais submetidos à restrição alimentar ou abatidos com maior peso e alimentados ad libitum e verificaram que, mesmo quando os animais são submetidos à restrição alimentar, por longo período de tempo, o coração e os pulmões mantêm sua integridade, apresentando prioridade na utilização dos nutrientes. No entanto, esses autores constataram que o peso do fígado, em relação ao peso corporal vazio, reduz-se em animais submetidos a baixo nível nutricional.

De maneira geral, o peso percentual dos órgãos internos de animais abatidos mais pesados (mais velhos) em relação aos mais leves (mais jovens) representa menor proporção do peso corporal vazio (JORGE, 1993). Segundo BERG e BUTTERFIELD, (1976) isto ocorre porque os órgãos vitais apresentam maior desenvolvimento em fase mais precoce da vida do animal e, à medida que a idade do animal avança, a velocidade de crescimento dos tecidos muscular e principalmente do adiposo é maior, passando os órgãos internos a representarem menor proporção do peso corporal vazio.

O objetivo deste trabalho foi estudar o tamanho (peso) dos órgãos (coração, fígado, baço e pulmões) e das vísceras (compartimentos do TGI) em zebuínos de quatro raças, submetidos à alimentação restrita e ad libitum.

\section{Material e Métodos}

O presente estudo foi realizado na Universidade Federal de Viçosa. Foram utilizados dados de 63 bovinos machos não-castrados, sendo 16 Gir (GIR), 16 Guzerá (GUZ), 15 Nelore (NEL) e 16 Mocho Tabapuã (TAB), com idade média de 24 meses e pesos médios iniciais de 357,6 $\pm 32,95 ; 362,0 \pm 28,95$; $376,4 \pm 28,56$; e $368,6 \pm 25,83 \mathrm{~kg}$, respectivamente, provenientes da EPAMIG, Minas Gerais. Estes animais foram confinados em baias individuais concretadas com área de $30 \mathrm{~m}^{2}$, oito das quais eram cobertos com telhas de fibro-cimento. As baias dispunham de comedouro e bebedouro de cimento.

Os animais de cada raça foram distribuídos em cinco grupos, cada um designado, aleatoriamente, para um dos tratamentos (categorias): abate inicial ou referência (AB); alimentação restrita (AR); e alimentação ad libitum até o abate, a peso vivo de 405, 450 e $500 \mathrm{~kg}$, equivalente a 90, 100 e $110 \%$ do peso estimado à maturidade das fêmeas da raça (categoria 1 , 2 e 3), respectivamente. No tratamento $A B$ foram alocados quatro animais das raças Gir, Guzerá e MochoTabapuã e três da raça Nelore. Nos demais tratamentos foram alocados três animais de cada raça.

Os animais das categorias 1, 2 e 3 receberam, durante o período experimental, ração balanceada $\mathrm{ad}$ libitum, formulada segundo as normas do NRC (1984), de modo a permitir ganho diário de $1,1 \mathrm{~kg}$, atendendo, ao mesmo tempo, às exigências de proteína degradável no rúmen (PDR) e proteína não-degradável no rúmen (PNDR), segundo o ARC (1980). Procurou-se sempre manter a proporção concentrado: volumoso próxima de 1:1, na matéria seca (MS). A ração foi fornecida aos animais da categoria AR em quantidades limitadas, de forma a ingerirem quantidades de energia e proteína $15 \%$ acima das exigências de mantença.

A composição percentual da ração experimental é apresentada na Tabela 1 e os teores de matéria seca (MS), proteína bruta (PB), energia metabolizável (EM) e macroelementos minerais dos ingredientes e da ração encontram-se na Tabela 2 .

O período experimental não teve duração pré-

Tabela 1 - Composição da ração experimental (\% MS) Table 1 - Composition of experimental diet (\% DM)

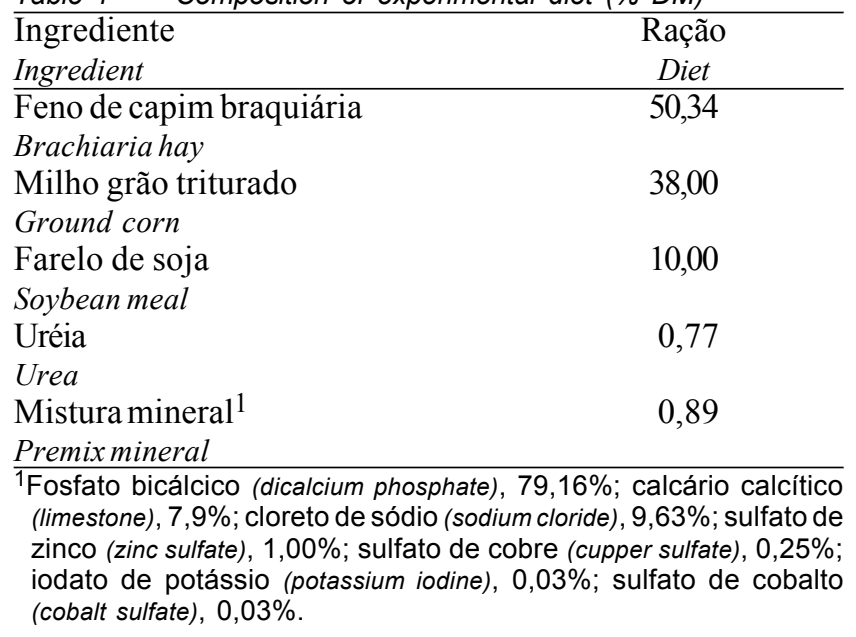


376 Rev. bras. zootec.

Tabela 2 - Composição química do feno, do concentrado e da ração experimental (\% MS)

Table 2 - Chemical composition of the hay, concentrate and diet (\% DM)

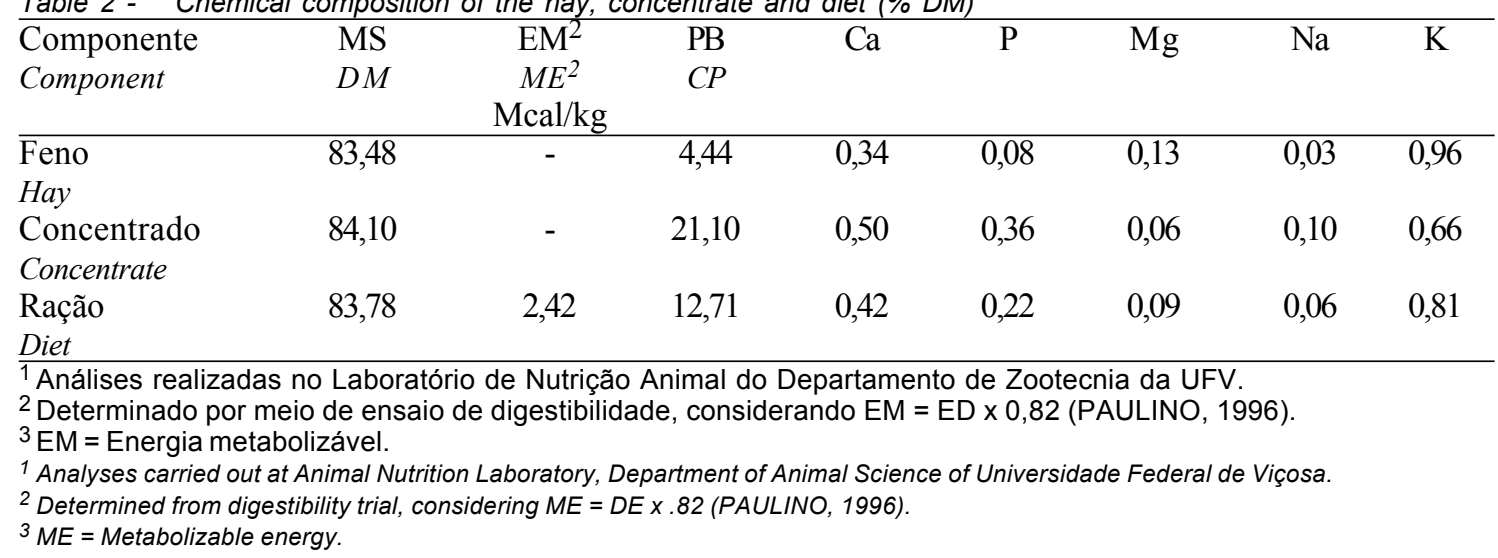

fixada, uma vez que os animais eram abatidos assim que atingiam os pesos pré-estabelecidos de $405,450 \mathrm{ou}$ $500 \mathrm{~kg}$, correspondentes aos tratamentos (categorias) 1, 2 e 3, respectivamente. Ao ser abatido um animal da categoria 2, era abatido um animal da categoria AR.

Ao atingir o peso de abate, o animal foi submetido a período de 16 horas de jejum, com acesso à água. Após o abate, os pesos de cabeça, pés, couro, trato gastrintestinal vazio, gordura interna, fígado, coração, rins, baço, pulmões, língua, sangue, mesentério, cauda, esôfago, traquéia e aparelho reprodutor foram registrados.

A carcaça foi dividida em duas metades, e estas pesadas individualmente e resfriadas por 18 horas, à temperatura de $-5^{\circ} \mathrm{C}$.

O peso corporal vazio dos animais AB foi determinado somando-se os pesos de carcaça, sangue, cabeça, pés, couro, cauda e vísceras. Relações específicas entre o peso corporal vazio e o vivo foram determinadas para animais de cada grupo genético e utilizadas para se estimar o peso corporal vazio inicial dos animais experimentais remanescentes. $\mathrm{O}$ peso corporal vazio final desses animais foi determinado de modo semelhante aos animais-referência.

As análises estatísticas foram feitas utilizandose o programa LSMLWM, versão PC-1, segundo HARVEY (1987), utilizando-se o modelo abaixo:

em que

$$
Y_{i j k}=\mu+R_{i}+C_{j}+R C_{i j}+e_{i j k}
$$

$\mathrm{Y}_{\mathrm{ijk}}=$ observação referente ao animal k, da raça i e categoria $\mathrm{j}$;

$\mu=$ média geral;

$\mathrm{R}_{\mathrm{i}}=$ efeito da raça $\mathrm{i}$, em que $\mathrm{i}=1$, (GIR);2, (GUZ); 3,(NEL); 4, (TAB);

$\mathrm{C}_{\mathrm{j}}=$ efeito da categoria $\mathrm{j}$, em que $\mathrm{j}=1,(\mathrm{AB}) ; 2$ (AR); 3 (I); 4 (II) e 5 (III);

$\mathrm{RC}_{\mathrm{ij}}=$ efeito da interação entre raça i e categoria $\mathrm{j}$; e $\mathrm{e}_{\mathrm{ijk}}=$ erro aleatório, pressuposto normalmente distribuído, com média zero e variância $\sigma^{2}$.

As médias foram comparadas pelo teste Tukey, a $5 \%$ de probabilidade.

\section{Resultados e Discussão}

As análises de variância para as características em estudo mostraram não haver efeito significativo de interação entre raças (GIR, GUZ, NEL e TAB) e categorias (AB, AR, 1, 2 e 3), sendo, portanto, os dois efeitos considerados independentes.

Os pesos médios de coração, fígado, baço, pulmões e conjunto coração - fígado - baço - pulmões (CFBP) são apresentados na Tabela 3. Na Tabela 4 são apresentados os pesos médios de intestino delgado (ID), intestino grosso (IG), conjunto intestinos (ID $+\mathrm{IG}$ ), rúmen-retículo (RURET), omaso, abomaso, estômagos (EST) e trato gastrintestinal (TGI), para os animais das raças estudadas.

Não houve diferença entre raças quanto ao peso do CFBP por $100 \mathrm{~kg}$ de PCVZ. Os valores encontrados de peso do CFBP para o Nelore foram 7,69 e $8,42 \%$ superiores ao valores encontrados por JORGE (1993) e PERON et al. (1993), respectivamente, e $8,39 \%$ inferiores aos observados por GAZZETTA et al. (1995). Animais europeu ou mestiços de raças leiteiras tendem a apresentar maior massa de órgãos internos, em relação ao peso vivo, que os zebuínos (PERON et al., 1993; JORGE, 1993). Segundo FERREL et al.(1976), as diferenças nas exigências de energia líquida para mantença entre grupos genéticos podem ser, em parte, explicadas por diferenças no tamanho de seus órgãos internos, que são maiores nos taurinos que nos zebuínos.

De maneira geral, não houve diferença entre 
JORGE et al.

Tabela 3 - Média dos pesos de coração, fígado, baço, pulmões e conjunto coração-fígado-baço-pulmões $(\mathrm{CFBP})^{1}$, em animais Gir (GIR), Guzerá (GUZ), Nelore (NEL) e Mocho Tabapuã (TAB)

Table 3 - Mean of the weights of heart, liver, spleen, lungs and heart-liver-spleen-lungs set (HLSL) ${ }^{1}$ from the animals Gyr (GIR), Guzera (GUZ), Nellore (NEL) and Mocho de Tabapuã (TAB)

\begin{tabular}{|c|c|c|c|c|}
\hline \multirow[t]{2}{*}{ Item } & \multicolumn{4}{|c|}{$\begin{array}{l}\text { Raça } \\
\text { Breed }\end{array}$} \\
\hline & GIR & GUZ & NEL & TAB \\
\hline & \multicolumn{4}{|c|}{ 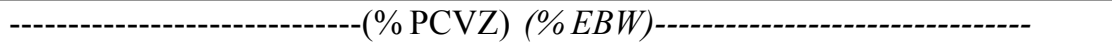 } \\
\hline Coração & $0,37 \pm 0,01 \mathrm{ab}$ & $0,35 \pm 0,01 b$ & $0,37 \pm 0,01 \mathrm{ab}$ & $0,39 \pm 0,01 \mathrm{a}$ \\
\hline Heart & & & & \\
\hline Fígado & $1,42 \pm 0,03 \mathrm{a}$ & $1,38 \pm 0,03 \mathrm{a}$ & $1,38 \pm 0,03 \mathrm{a}$ & $1,41 \pm 0,03 \mathrm{a}$ \\
\hline Liver & & & & \\
\hline Baço & $0,29 \pm 0,01 \mathrm{a}$ & $0,27 \pm 0,01 \mathrm{a}$ & $0,27 \pm 0,01 \mathrm{a}$ & $0,27 \pm 0,01 \mathrm{a}$ \\
\hline Spleen & & & & \\
\hline Pulmões & $0,67 \pm 0,03 \mathrm{ab}$ & $0,64 \pm 0,03 b$ & $0,71 \pm 0,03 \mathrm{a}$ & $0,72 \pm 0,03 \mathrm{ab}$ \\
\hline Lungs & & & & \\
\hline $\mathrm{CFBP}^{1}$ & $2,75 \pm 0,05 \mathrm{a}$ & $2,64 \pm 0,05 \mathrm{a}$ & $2,73 \pm 0,05 a$ & $2,79 \pm 0,05 \mathrm{a}$ \\
\hline
\end{tabular}

Médias, na linha, seguidas de letras diferentes são diferentes $(P<0,05)$ pelo teste Tukey.

1 CFBP = coração + fígado + baço + pulmões.

Means, within a row, followed by different letter are different $(P<.05)$ by Tukey test.

1 HLSL $=$ heart + liver + spleen + lungs.

Tabela 4 - Média dos pesos de intestino delgado (ID), intestino grosso (IG), intestinos (ID + IG), rúmenretículo (RURET), omaso e abomaso, estômagos (EST) ${ }^{1}$ e trato gastrintestinal $(T G I)^{2}$, em animais Gir (GIR), Guzerá (GUZ), Nelore (NEL) e Mocho Tabapuã (TAB)

Table 4 - Mean of the weights of small intestine (SI), large intestine (LI), intestines (SI + LI), reticulo-rumen (RETRU), omasum and abomasum, stomach (STO) and gastrintestinal tract (GTI) from the animals Gyr (GIR), Guzera (GUZ), Nellore (NEL) and Mocho de Tabapuã (TAB)

\begin{tabular}{|c|c|c|c|c|}
\hline \multirow[t]{2}{*}{ Item } & \multicolumn{4}{|c|}{$\begin{array}{l}\text { Raça } \\
\text { Breed }\end{array}$} \\
\hline & GIR & GUZ & NEL & TAB \\
\hline & \multicolumn{4}{|c|}{$\begin{array}{c}\% \text { Peso corporal vazio }(\% \mathrm{PCVZ}) \\
\% \text { Empty body weight }(\% E B W)\end{array}$} \\
\hline ID & $1,18 \pm 0,03 \mathrm{a}$ & $1,25 \pm 0,03 \mathrm{a}$ & $1,16 \pm 0,04 \mathrm{a}$ & $1,26 \pm 0,03 \mathrm{a}$ \\
\hline$S I$ & & & & \\
\hline IG & $0,83 \pm 0,03 \mathrm{a}$ & $0,90 \pm 0,03 \mathrm{a}$ & $0,83 \pm 0,03 \mathrm{a}$ & $0,83 \pm 0,03 \mathrm{a}$ \\
\hline$L I$ & & & & \\
\hline $\begin{array}{l}\mathrm{ID}+\mathrm{IG} \\
S I+L I\end{array}$ & $2,01 \pm 0,05 \mathrm{a}$ & $2,15 \pm 0,05 \mathrm{a}$ & $1,99 \pm 0,05 \mathrm{a}$ & $2,09 \pm 0,05 \mathrm{a}$ \\
\hline $\begin{array}{l}\text { RURET } \\
\text { RETRU }\end{array}$ & $2,01 \pm 0,05 \mathrm{a}$ & $1,95 \pm 0,05 \mathrm{a}$ & $1,93 \pm 0,05 \mathrm{a}$ & $1,92 \pm 0,05 \mathrm{a}$ \\
\hline Omaso & $0,75 \pm 0,04 \mathrm{a}$ & $0,73 \pm 0,04 \mathrm{a}$ & $0,74 \pm 0,04 \mathrm{a}$ & $0,75 \pm 0,04 \mathrm{a}$ \\
\hline Omasum & & & & \\
\hline $\begin{array}{l}\text { Abomaso } \\
\text { Abomasum }\end{array}$ & $0,27 \pm 0,01 b$ & $0,32 \pm 0,01 \mathrm{a}$ & $0,29 \pm 0,01 \mathrm{ab}$ & $0,29 \pm 0,01 \mathrm{ab}$ \\
\hline $\begin{array}{l}\mathrm{EST}^{1} \\
\mathrm{STO}^{1}\end{array}$ & $3,03 \pm 0,06 \mathrm{a}$ & $3,00 \pm 0,06 \mathrm{a}$ & $2,96 \pm 0,06 \mathrm{a}$ & $2,96 \pm 0,06 \mathrm{a}$ \\
\hline $\begin{array}{l}\mathrm{TGI}^{2} \\
G I T \\
\end{array}$ & $5,04 \pm 0,09 a$ & $5,15 \pm 0,09 a$ & $4,95 \pm 0,09 a$ & $5,05 \pm 0,09 a$ \\
\hline $\begin{array}{l}\text { Médias, ne } \\
1 \text { EST = estô } \\
2 \text { TGI = trato } \\
\text { Means, with } \\
1 \text { STO = stome } \\
{ }^{2} \mathrm{GTI}=\text { gastri }\end{array}$ & $\begin{array}{l}\text { le letras difere } \\
\text { omaso +abom } \\
+ \text { IG + RURET } \\
\text { different letter } \\
m+\text { abomasum). } \\
+ \text { RETRU + oma }\end{array}$ & $\begin{array}{l}\text { diferentes }(\mathrm{P}<0 \\
+ \text { abomaso). } \\
t(P<.05) \text { by Tuke } \\
\text { masum). }\end{array}$ & teste Tukey. & \\
\hline
\end{tabular}


378 Rev. bras. zootec.

raças quanto ao peso das vísceras brancas (intestinos e estômagos), por $100 \mathrm{~kg}$ de PCVZ. Resultados similares de peso de TGI para a raça Nelore, expressos por $100 \mathrm{~kg}$ de PCVZ, foram observados por OLIVEIRA et al.(1992), JORGE (1993), OLIVEIRA et al. (1994) e GAZZETTA et al., (1995), que encontraram os valores de 4,37; 4,40; 5,1; e 5,72\%, respectivamente. Animais com sangue da raça Holandesa têm apresentado maiores pesos para o TGI que zebuínos e seus mestiços com taurinos de corte, provavelmente, em conseqüência de a seleção ser voltada principalmente para produção de leite, que exige maior consumo de alimento, especialmente no caso de altas produtoras, em relação à produção de carne (PERON et al., 1993; JORGE , 1993).

Na Tabela 5, são apresentados os pesos médios de coração, fígado, baço, pulmões e CFBP e na Tabela 6, os pesos médios de ID, IG, (ID +IG), RURET, omaso, abomaso, EST e TGI, para as categorias estudadas.

Para os pesos do conjunto CFPB, baço e pulmões, por $100 \mathrm{~kg}$ de PCVZ, não se verificou diferença entre a categoria $A R$ e as categorias de ganho (1, 2 e 3), o que, de certa forma, indica que, mesmo quando os animais são submetidos à baixa restrição alimentar, por longo período de tempo, estes órgãos mantêm sua integridade, mostrando prioridade na utilização dos nutrientes.
Animais AB apresentaram maior peso de intestino delgado que animais $\mathrm{AR}$ e animais abatidos com 500 $\mathrm{kg}$ de peso vivo (categoria 3 ), indicando que o aumento de peso desse componente do trato gastrintestinal ocorreu em ritmo mais lento que o peso corporal.

Animais da categoria mantença (AR) apresentaram menores pesos $(\mathrm{P}<0,05)$ relativos de EST e TGI que animais de abate inicial ( $A B)$. Isso indica que houve redução dessas vísceras quando os animais foram submetidos à restrição alimentar. Estes resultados coincidem com os de PERON et al.(1993), JORGE (1993) e OLIVEIRA et al. (1994), ao abaterem bovinos sob alimentação restrita e ad libitum.

Os menores $(\mathrm{P}<0,05)$ pesos verificados para estômago (EST) e trato gastrintestinal (TGI) dos animais AR, por $100 \mathrm{~kg}$ de PCVZ, confirmam as observações de HOGG (1991).

O omaso e o abomaso mantiveram desenvolvimento proporcional ao peso do animal, conforme indicam os seus pesos em relação a $100 \mathrm{~kg}$ de peso corporal vazio.

Não se observou diferença nos pesos de RURET, omaso e abomaso, expressos por $100 \mathrm{~kg}$ de PCVZ, entre as categorias de ganho (I, II e III), submetidas à alimentação ad libitum, apesar da tendência de declínio no peso dos mesmos, à medida que se elevou o peso corporal vazio.

Tabela 5 - Média dos pesos de coração, fígado, baço, pulmões e conjunto coração-fígado-baço-pulmões $(\mathrm{CFBP})^{1}$, em animais das diferentes categorias

Table 5 - Mean of the weights of heart, liver, spleen, lungs and heart-liver-spleen-lungs set (HLSL) ${ }^{1}$ of animals from different categories

\begin{tabular}{|c|c|c|c|c|c|}
\hline \multirow[t]{2}{*}{ Item } & \multicolumn{5}{|c|}{$\begin{array}{c}\text { Categoria }^{2} \\
\text { Category }\end{array}$} \\
\hline & $\begin{array}{l}\mathrm{AB} \\
I S\end{array}$ & $\begin{array}{l}\mathrm{AR} \\
R F\end{array}$ & 1 & 2 & 3 \\
\hline $\begin{array}{l}\text { Coração } \\
\text { Heart }\end{array}$ & $0,40 \pm 0,01 \mathrm{a}$ & $0,42 \pm 0,01 \mathrm{a}$ & $\begin{array}{l}\text { Z) }(\% E B W) \\
0,35 \pm 0,01 \mathrm{~b}\end{array}$ & $0,35 \pm 0,01 \mathrm{~b}$ & $0,34 \pm 0,01 b$ \\
\hline $\begin{array}{l}\text { Fígado } \\
\text { Liver }\end{array}$ & $1,53 \pm 0,03 \mathrm{a}$ & $1,20 \pm 0,03 \mathrm{c}$ & $1,42 \pm 0,03 b$ & $1,38 \pm 0,03 b$ & $1,46 \pm 0,03 b$ \\
\hline $\begin{array}{l}\text { Baço } \\
\text { Spleen }\end{array}$ & $0,26 \pm 0,01 \mathrm{a}$ & $0,26 \pm 0,01 \mathrm{a}$ & $0,28 \pm 0,01 \mathrm{a}$ & $0,28 \pm 0,01 \mathrm{a}$ & $0,28 \pm 0,01 \mathrm{a}$ \\
\hline $\begin{array}{l}\text { Pulmões } \\
\text { Lungs }\end{array}$ & $0,77 \pm 0,03 \mathrm{a}$ & $0,69 \pm 0,03 \mathrm{a}$ & $0,68 \pm 0,03 \mathrm{a}$ & $0,65 \pm 0,03 \mathrm{a}$ & $0,63 \pm 0,03 \mathrm{a}$ \\
\hline $\begin{array}{l}\text { CFBP }^{1} \\
H L S L\end{array}$ & $2,96 \pm 0,05 \mathrm{a}$ & $2,57 \pm 0,06 b$ & $2,73 \pm 0,06 b$ & $2,66 \pm 0,06 b$ & $2,71 \pm 0,06 b$ \\
\hline
\end{tabular}

Médias, na linha, seguidas de letras diferentes são diferentes $(P<0,05)$ pelo teste Tukey.

${ }^{1} \mathrm{CFBP}=$ coração + fígado + baço + pulmões

${ }^{2} \mathrm{AB}=$ Abate inicial (animais-referência); $\mathrm{AR}=$ alimentação restrita; $1=405 \mathrm{~kg} \mathrm{PV} ; 2=450 \mathrm{~kg} \mathrm{PV} ; 3=500 \mathrm{~kg}$ PV.

Means, within a row, followed by different letter are different $(P<.05)$ by Tukey test.

${ }^{1} \mathrm{HLSL}=$ heart + liver + spleen + lungs.

${ }^{2}$ IS = Immediate slaughter; $R F=$ restricted feeding, $1=405 \mathrm{~kg} \mathrm{LW} ; 2=450 \mathrm{~kg} \mathrm{LW} ; 3=500 \mathrm{~kg} \mathrm{LW}$. 
JORGE et al.

Tabela 6 - Média dos pesos de intestino delgado (ID), intestino grosso (IG), intestinos (ID + IG), rúmen-retículo (RURET), omaso e abomaso, estômagos (EST) ${ }^{1}$ e trato gastrintestinal $(T G I)^{2}$, em animais das diferentes categorias

Table 6 - Mean of weights of small intestine (SI), large intestine (LI), intestines (SI + LI), reticulo-rumen (RETRU), omasum and abomasum, stomach (STO) and gastrintestinal tract (GTI) of animals from different categories

\begin{tabular}{|c|c|c|c|c|c|}
\hline \multirow[t]{2}{*}{ Item } & \multicolumn{5}{|c|}{$\begin{array}{c}\text { Categoria }^{3} \\
\text { Category }\end{array}$} \\
\hline & $\mathrm{AB}(I S)$ & $\mathrm{AR}(R F)$ & $\begin{array}{c}1 \\
(\% \mathrm{PCVZ})(\% E B W)\end{array}$ & 2 & 3 \\
\hline$\overline{\mathrm{ID}}$ & $1,32 \pm 0,04 \mathrm{a}$ & $1,10 \pm 0,04 b$ & $1,30 \pm 0,04 \mathrm{a}$ & $1,22 \pm 0,04 \mathrm{ab}$ & $1,11 \pm 0,04 b$ \\
\hline IG & $0,95 \pm 0,03 \mathrm{a}$ & $0,83 \pm 0,03 \mathrm{ab}$ & $0,86 \pm 0,03 \mathrm{ab}$ & $0,78 \pm 0,03 b$ & $0,81 \pm 0,03 b$ \\
\hline$L I$ & & & & & \\
\hline $\begin{array}{l}\mathrm{ID}+\mathrm{IG} \\
S I+L I\end{array}$ & $2,27 \pm 0,05 \mathrm{a}$ & $1,93 \pm 0,06 b$ & $2,16 \pm 0,06 \mathrm{ab}$ & $2,00 \pm 0,06 b$ & $1,92 \pm 0,06 \mathrm{~b}$ \\
\hline RURET & $2,28 \pm 0,05 \mathrm{a}$ & $1,78 \pm 0,05 b$ & $2,00 \pm 0,05 b$ & $1,88 \pm 0,05 b$ & $1,82 \pm 0,05 b$ \\
\hline Omaso & $0,82 \pm 0,04 \mathrm{a}$ & $0,65 \pm 0,05 \mathrm{a}$ & $0,82 \pm 0,05 \mathrm{a}$ & $0,73 \pm 0,05 \mathrm{a}$ & $0,69 \pm 0,05 \mathrm{a}$ \\
\hline $\begin{array}{l}\text { Omasum } \\
\text { Abomaso }\end{array}$ & & & & & \\
\hline $\begin{array}{l}\text { Abomasum } \\
\text { EST }^{1}\end{array}$ & $\begin{array}{l}0,30 \pm 0,01 \mathrm{a} \\
3,40 \pm 0,06 \mathrm{a}\end{array}$ & $\begin{array}{l}0,30 \pm 0,01 \mathrm{a} \\
2,73 \pm 0,07 \mathrm{c}\end{array}$ & $\begin{array}{l}0,30 \pm 0,01 \mathrm{a} \\
3,12 \pm 0,07 \mathrm{~b}\end{array}$ & $\begin{array}{c}0,29 \pm 0,01 \mathrm{a} \\
2,90 \pm 0,07 \mathrm{bc}\end{array}$ & $\begin{array}{l}0,28 \pm 0,01 \mathrm{a} \\
2,79 \pm 0,07 \mathrm{c}\end{array}$ \\
\hline $\begin{array}{l}S T O^{1} \\
\text { TGI }^{2} \\
G I T^{2} \\
\end{array}$ & $5,67 \pm 0,09 a$ & $4,66 \pm 0,10 \mathrm{c}$ & $5,28 \pm 0,10 b$ & $4,90 \pm 0,10 b c$ & $4,71 \pm 0,10 \mathrm{c}$ \\
\hline $\begin{array}{l}\text { Médias, na } \\
{ }^{1} \mathrm{EST}=\text { estô } \\
2 \mathrm{TGI}=\text { trato } \\
{ }^{3} \mathrm{AB}=\text { abate } \\
\text { Means, withi } \\
{ }^{1} \mathrm{STO}=\text { stoma } \\
{ }^{2} \mathrm{GTI}=\text { gastrin } \\
{ }^{3} \mathrm{IS}=\text { immedic }\end{array}$ & $\begin{array}{l}\text { seguidas de le } \\
\text { (RURET + Om } \\
\text { testinal (ID + IC } \\
\text { (animais-referê } \\
\text { followed by diff } \\
R U+\text { omasum +a } \\
\text { tract }(S I+L I+R \\
\text { ghter; } R F=\text { restri }\end{array}$ & $\begin{array}{l}\text { diferentes são } \\
\text {-Abomaso). } \\
\text { URET + Omasc } \\
\text {; AR = alimenta } \\
\text { letter are differen } \\
\text { sum) } \\
+ \text { omasum + abo }\end{array}$ & $\begin{array}{l}\text { ferentes }(P<0,05) \text { pelo } \\
\text { Abomaso }) \text {. } \\
\text { ao restrita; } 1=405 \mathrm{~kg} \mathrm{de} \\
(P<.05) \text { by Tukey test. } \\
\text { (sum) } \\
W \cdot 2=450 \mathrm{~kg} L W \cdot 3=50\end{array}$ & $\begin{array}{l}\text { teste Tukey. } \\
\text { PV; } 2=450 \mathrm{~kg} \mathrm{c}\end{array}$ & ; $3=500 \mathrm{~kg}$ de $P V$ \\
\hline
\end{tabular}

\section{Conclusões}

Não houve diferenças entre raças nos pesos de fígado, baço e CFBP e nos pesos do ID, IG, RURET, omaso, EST e TGI, quando expressos por $100 \mathrm{~kg}$ de PCVZ.

A restrição alimentar não acarretou redução nos pesos do coração e pulmões, ao contrário do que se verificou para o fígado e para os componentes do TGI.

\section{Referências Bibliográficas}

AGRICULTURAL RESEARCH COUNCIL - ARC. 1980. The nutrient requirements of ruminants livestock. London: Commonwealth Agricultural Bureaux, 351p.

BERG. R. T., BUTTERFIELD, R. M. 1976. New concepts of cattle growth. New York: Sydney University, 240p.

FERRELL, C. L., GARRETT, W. N., HINMAN, N. et al. 1976. Energy utilization by pregnant heifers. J. Anim. Sci., 42(4):937-950.

GALVÃO, J. G., FONTES, C. A. A., PIRES, C. C. et al. 1991 b. Características e composição física da carcaça de bovinos não castrados, abatidos em três estágios de maturidade (estudo II) de três grupos raciais. R. Soc. Bras. Zootec., 20(5):502-512.

GALVÃO, J. G., FONTES, C. A. A., PIRES, C. C. et al. 1991a. Ganho de peso, consumo e conversão alimentar em bovinos não-castrados, de três grupos raciais, abatidos em diferentes estágios de maturidade (estudo I). R. Soc. Bras. Zootec., 20(5):494-501.

GAZZETTA, M. C. R. R., ITURRINO, R. P. S., CAMPOS, B. E. S. et al. 1995. Avaliação corporal de búfalos (Bubalus bubalis) e bovinos nelore (Bos indicus), terminados em confinamento. Bol. Ind. Anim., 52(1):77-86.

GONÇALVES, L. C. Digestibilidade, composição corporal, exigências nutricionais e características das carcaças de zebuínos, taurinos e bubalinos. Viçosa, MG: UFV, 1988. 238p. Tese (Doutorado em Zootecnia) - Universidade Federal de Viçosa, 1988.

HARVEY, W. R.1987. Mixed model least squares and maximum likelihood computer program (LSMLWM) Versão PC - 1.

HOGG, B. W. 1991. Compensatory growth in ruminants. In: PEARSON, A. M., DUTSUN, T. R. (eds) Growth regulation in farm animals - Advance in meat science research. v. 7, London: Elsevier Applied Science, p.105.

JORGE, A. M.1993. Ganho de peso, conversão alimentar e características da carcaça de bovinos e bubalinos. Viçosa, MG: UFV, 1993. 97p. Dissertação (Mestrado em Zootecnia) - Universidade Federal de Viçosa, 1993. 
380 Rev. bras. zootec.

NATIONAL RESEARCH COUNCIL - NRC. 1984. Nutrient requeriments of beef cattle. 6. ed. Washington, D. C., 90p.

OLIVEIRA, M. A. T. de, FONTES, C. A. A., LANA, R. de P. et al. 1994. Biometria do trato gastrintestinal e área corporal de bovinos. R. Soc. Bras. Zootec., 23(4):576-584.

OLIVEIRA, R. F. M., FONTES, C. A. A., CARNEIRO, L. H. D. et al.1992. Biometria do trato gastrintestinal de bovinos de três grupos genéticos. R. Soc. Bras. Zootec., 21(2):205-210.

PAULINO, M. F. Composição corporal e exigências de energia, proteina e macroelementos minerais ( $\mathrm{Ca}, \mathrm{P}, \mathrm{Mg}, \mathrm{Na}$ e K) de bovinos não-castrados de quatro raças zebuínas em confinamento. Viçosa, MG: UFV, 1996. 80p. Tese (Doutorado em Zootecnia) - Universidade Federal de Viçosa, 1996.

PERON, A. J., FONTES, C. A. A., LANA, R. P. et al. 1993.

Tamanho de órgãos internos e distribuição da gordura corpo- ral, em novilhos de cinco grupos genéticos,submetidos a alimentação restrita e ad libitum. R. Soc. Bras. Zootec., 22(5):813-819.

SMITH, N. E., BALDWIN, R. L. 1973. Effects of breed, pregnancy and lactation on weight of organs and tissues in dairy catle. J. Dairy Sci., 57:1055.

Recebido em: 24/02/97

Aceito em: 02/09/98 